\title{
Positivismo e marxismo: o debate sobre a neutralidade científica e a construção do projeto profissional do Serviço Social brasileiro
}

\author{
Positivism and Marxism: the debate on scientific neutrality and the construction of the \\ professional project of the Brazilian Social Work
}

\section{Bárbara da Rocha Figueiredo Chagas*}

\begin{abstract}
Resumo:
O presente artigo apresenta a sistematização de reflexões teóricas acerca do debate da neutralidade nas ciências sociais e sua influência no Serviço Social brasileiro. A partir da apresentação da concepção de neutralidade científica defendida pela perspectiva positivista e sua contraposição a partir da teoria social marxista, faz-se uma reflexão sobre a relação deste debate e sua histórica influência nas ciências sociais e no Serviço Social brasileiro. Retoma-se o movimento de rupturas e continuidades na trajetória de construção de um projeto profissional crítico para o Serviço Social, problematizando a existência de diferentes opções teórico-políticas que o corpo profissional pode adotar, individual e/ou coletivamente.
\end{abstract}

Palavras-chave: Neutralidade. Positivismo. Marxismo. Serviço social. Projeto profissional.

\begin{abstract}
:
This article presents the systematization of theoretical reflections on the neutrality debate in the social sciences and their influence in the Brazilian Social Work. From the presentation of scientific neutrality conception supported by the positivist perspective and his opposition from the Marxist social theory, it is a reflection on relationship of this debate and its historical influence in the social sciences and the Brazilian Social Work. The movement of ruptures and continuities is taken up in the path of building a critical project for professional social work, questioning the existence of different theoretical and policy options that the professional body can take, individually and/or collectively.
\end{abstract}

Key Words: Neutrality. Positivism. Marxism. Social Work. Professional project.

\section{Introdução}

O debate sobre a possibilidade do alcance da neutralidade nas ciências sociais não é novo. Ele tem atravessado toda a história da sociologia. De Auguste Comte a Max Weber, diversos estudiosos positivistas ou parcialmente situados neste campo buscaram elaborar teses que justificassem não apenas a neutralidade do pesquisador em relação ao objeto pesquisado, mas também o uso da neutralidade como único caminho possível para

\footnotetext{
* Assistente Social. Doutoranda em Serviço Social pela Universidade Federal do Rio de Janeiro. E-mail: barbaraufri@outlook.com
} 
alcançar a "verdade científica". Esta tese galgou grande influência nas Ciências Sociais e repercutiu fortemente no Serviço Social brasileiro, mesmo após a maturidade da relação deste com o referencial teórico-metodológico marxista.

Cabe, portanto, engendrar uma reflexão acerca da tese positivista de neutralidade científica e das elaborações marxistas sobre o tema, relacionando-o ao processo de construção de um projeto profissional crítico do Serviço Social, no sentido de fornecer elementos teórico-metodológicos que fortaleçam a perspectiva crítica presente hegemonicamente entre os assistentes sociais brasileiros.

\title{
Positivismo, marxismo e o mito da neutralidade ideológica
}

A hipótese fundamental do positivismo é de que a sociedade, a vida social, é regida por leis naturais universais e invariáveis. E que, nesse sentido, a melhor metodologia para conhecer a vida social seria a mesma empregada para estudar a vida natural: a observação com objetividade científica - neutra, livre das ideologias.

\begin{abstract}
Significa que a concepção positivista é aquela que afirma a necessidade e a possibilidade de uma ciência social completamente desligada de qualquer vínculo com as classes sociais, com as posições políticas, os valores morais, as ideologias, as utopias, as visões de mundo. Todo esse conjunto de elementos ideológicos, em seu sentido amplo, deve ser eliminado da ciência social (LÖWY, 1985, p. 39).
\end{abstract}

A busca pela verdade objetiva, pela identificação e análise das leis universais que regem os fenômenos sociais seria, portanto, a única forma de conceder aos resultados da pesquisa uma valoração universal. O meio para isso seria uma espécie de "autoneutralização ideológica" do cientista social. O que possui uma clara implicação conservadora, concebendo os fenômenos sociais como imutáveis, e seus males inevitáveis, cabe aos sujeitos - e ao pesquisador - um claro papel de resignação e conformação.

É por isso que de forma bastante sintética Durkheim afirma que o positivismo "[...] não tem nada de revolucionário, pelo contrário, ele é essencialmente conservador, porque considera os fatos sociais como coisas cuja natureza, por mais maleável que seja, não pode ser modificada pela vontade humana" (apud LÖWY, 2008, p. 48).

O caráter conservador do positivismo relaciona-se à suas raízes históricas. Auguste Comte, um dos fundadores da teoria positivista, a formula em um período posterior à 
Revolução Francesa, quando a burguesia havia ascendido ao poder e lutava pela sua manutenção contra os interesses da nascente classe trabalhadora - um momento de grandes convulsões sociais e políticas. Nesse período, desenvolvem-se ideologias para dar sustentação aos interesses que disputavam os rumos da história. Comte vincula-se à parcela da burguesia que defendia um regime ditatorial e buscava impedir qualquer ameaça revolucionária.

Não por acaso, o positivismo apresentou-se como uma das teorias sociais que embasaram os primeiros passos da construção de um referencial teórico para o Serviço Social brasileiro. Ambos, o positivismo e o Serviço Social, possuem raízes conservadoras que se expressam, entre outras formas, por meio da naturalização da existência da pobreza. Com um projeto profissional enraizado no conservadorismo, ligado à Igreja Católica, os assistentes sociais brasileiros partiam do pressuposto de que as desigualdades sociais eram naturais e, portanto, insuperáveis.

A opção hegemônica do Serviço Social brasileiro, até o período de renovação em meados da década de 1960, era de vinculação a um projeto profissional conservador, ligado a uma direção social burguesa, de manutenção da hegemonia das classes dominantes e uma opção teórica positivista-funcionalista. Considera-se importante ressaltar este fato, dado que o Serviço Social brasileiro passou a declarar possuir um projeto profissional apenas nos idos de 1990, quando ganha hegemonia um projeto crítico no seio da categoria de assistentes sociais no Brasil. O fato é, entretanto, que antes da conquista da hegemonia do projeto profissional crítico existia um projeto profissional conservador, embora este não fosse declarado.

Em uma perspectiva contrária à do positivismo, a teoria social de Marx - elaborada, também, no período de nascimento do capitalismo - não objetivava manter, mas analisar criticamente o modelo social que surgia. Buscava entender as transformações correntes do ponto de vista dos interesses da classe trabalhadora - a classe que poderia cumprir um papel revolucionário. Marx não buscava elaborar uma ciência neutra, de valoração universal. Pretendia justamente o oposto.

Numa palavra: Marx considerava sua ciência como revolucionária e proletária e, como tal, oposta (e superior) à ciência conservadora e burguesa dos economistas clássicos. O "corte" entre Marx e seus predecessores é para ele um corte de classe no interior da história da ciência econômica (LÖWY, 2008, p. 19) 
A transparência com que Marx expunha o conteúdo e os objetivos de sua teoria demarcando-a com um claro interesse de classe - possuem uma explicação histórica. A burguesia, ao fazer a sua revolução, defendia seus interesses de classe, que eram antagônicos aos interesses das grandes massas. Pois, ao mesmo tempo que pretendia criar uma nova sociedade, pondo fim ao feudalismo, desejava constituir-se enquanto classe exploradora. Nesse sentido, as teorias burguesas buscavam - e continuam buscando - a compreensão parcial dos processos históricos: possuem um caráter de ocultação ideológica.

O marxismo, ao contrário, expressa as ideias de uma classe cujos interesses históricos são da maioria da humanidade. A classe trabalhadora é a primeira classe revolucionária cuja verdade absoluta lhe interessa. A primeira classe que não necessita camuflar seus propósitos, sua ideologia.

Como ilustra Löwy $(1985$, p. 32):

Não é, pois, absolutamente um acaso se o proletariado - ao contrário da burguesia revolucionária - apresenta abertamente sua revolução como sendo realizada, não em nome de pretensos "direitos naturais" ou de supostos "princípios eternos da Liberdade e da Justiça", mas em nome de seus interesses de classe. Uma comparação entre o Manifesto Comunista e a Declaração Universal dos Direitos do Homem de 1789 é altamente instrutiva a esse respeito!

Nesse sentido, o marxismo é a teoria social que busca entender os fenômenos sociais em sua essência, em sua totalidade. Ao marxismo - como a classe trabalhadora - interessa o conhecimento objetivo da realidade. Este é o seu interesse de classe, na medida em que é nas contradições da sociedade capitalista que se expressam de forma cada vez mais acirrada os antagônicos interesses de classe. O conhecimento dessas contradições é parte fundamental da tomada de consciência do proletariado em relação a sua situação de classe explorada. É imprescindível, portanto, para a transformação desta sociedade.

O marxismo situa-se em um campo absolutamente antagônico ao do positivismo e das ciências burguesas que difundem a neutralidade nas ciências sociais. O que os positivistas chamam de (pré)noções, ou (pré)conceitos do pesquisador, que devem ser eliminados para o conhecimento da verdade, a sociologia do conhecimento entende como um "conjunto de convicções, de ideias, de atitudes do investigador e também de seu grupo 
social, que escapa à dúvida, a qualquer questionamento, a qualquer distância crítica" (LÖWY, 1985, p. 48).

A neutralidade do cientista social é, dessa forma, inalcançável - na medida em que seu objeto de estudo, diferente das ciências naturais, situa-se no campo das relações sociais e é estudado sob concepções de sociedade diversas e antagônicas. É impossível, ao pesquisador, ignorar os conflitos ideológicos, afastar suas (pré)noções. A solução proposta pelo positivismo, de depositar sobre a boa vontade, o esforço e o empenho do cientista social a busca pela eliminação de suas próprias ideologias para a realização da pesquisa é uma proposta que não se materializa.

Isto porque, o que caracteriza as (pré)noções, ou o preconceito, é justamente a negação de que este seja um preconceito - ele é tido como evidente. Para eliminá-las, o pesquisador teria, primeiro, que as admitir como tal. Nesse sentido, o próprio positivismo jamais admitiu eliminar suas (pré)noções: a concepção de mundo a partir dos interesses burgueses. Esta concepção de mundo é tida como pressuposta, óbvia, única, certa e inquestionável.

Pressupondo a neutralidade do pesquisador como inalcançável, seria então a verdade objetiva também inatingível? O primeiro requisito para se alcançar a verdade científica, é pretendê-lo. O pressuposto é, portanto, óbvio: o pesquisador deve querer conhecer de fato o fenômeno social que pretende estudar.

Esse pré-requisito, entretanto, não resolve o problema do peso das ideologias na pesquisa social. Para o marxismo, o ponto de vista de classe irá interferir diretamente na capacidade de o pesquisador analisar os fenômenos sociais.

Não estamos afirmando que só os marxistas possuem capacidade de estudar e entender a realidade. Historicamente o melhor exemplo para o que estamos dizendo é a crítica de Marx ao economista burguês David Ricardo. Marx reconhece o valor da ciência produzida por Ricardo, mas critica enfaticamente suas limitações, que, para ele, deve-se ao fato do caráter burguês de seus estudos: Marx escreve que Ricardo, apesar de sua profundidade científica, é "prisioneiro do horizonte burguês". Não é que ele não queira entender o capitalismo, é que é impossível para ele ir além dos limites estruturais da visão burguesa" (LÖWY, 2008, p. 111). 
É por esse motivo que a crítica à economia política, formulada por Marx, supera a economia política clássica. A ciência burguesa, por mais que se pretenda, é incapaz de alcançar a verdade científica sobre a realidade social - pois essa verdade é antagônica aos interesses históricos da burguesia. Como dissemos anteriormente, é o marxismo o ponto de vista da classe trabalhadora, que pretende e pode desvendar o funcionamento da sociedade capitalista.

A tese positivista de neutralidade, no entanto, penetrou nas ciências sociais exercendo uma grande influência que ultrapassa o campo estritamente positivista. O poder da ideologia positivista exerceu influência inclusive sobre o próprio marxismo, não apenas nas correntes identificadas como revisionistas, mas também no interior do "marxismo ortodoxo" ${ }^{1}$. Nomes como Bernstein ${ }^{2}$ e Kautsky ${ }^{3}$ propuseram um marxismo menos "tendencioso", defendendo, por exemplo, que "O Capital seria uma obra ainda mais imparcial e científica, se o autor houvesse somado a seu gênio rigor e a seu amor à verdade a bela qualidade de se situar acima de todas as lutas e contradições de classes" (KAUTSKY apud LÖWY, 2013, p. 143).

Estas deformações na compreensão do pensamento marxiano fazem parte também das aproximações do Serviço Social brasileiro com a tradição marxista. Os passos iniciais na tentativa de ruptura com o conservadorismo profissional, dados pelo movimento de reconceituação (em meados da década de 1960), expressam uma aproximação ideológica ${ }^{4}$ com o marxismo. $\mathrm{O}$ acesso aos autores da teoria social crítica pela via da militância política fez com que "o nosso primeiro encontro com o marxismo [capturasse] deste os seus elementos ídeo-políticos, como aportes para a afirmação da ruptura em níveis mais gerais [...]" (SANTOS, 2015, p. 1).

A apreensão distorcida da teoria social de Marx não levou a uma ruptura radical com o conservadorismo. Embora essa experiência tenha tido um papel histórico relevante no processo de construção do Projeto Ético-Político profissional, as primeiras aproximações

\footnotetext{
${ }^{1}$ Termo utilizado por Santos (2015) ao referir-se aos setores reconhecidamente tradicionais do marxismo.

2 Eduard Bernstein foi um teórico político alemão do período da Segunda Internacional, considerado um revisionista do marxismo.

${ }^{3}$ Karl Kautsky foi um teórico político alemão do período da Segunda Internacional. Embora tenha sofrido diversas críticas por suas posições políticas em relação à Primeira Guerra Mundial, Kautsky era considerado um dos mais importantes teóricos de seu tempo, por ter sido "herdeiro" direto do marxismo - trabalhou diretamente com Engels.

${ }^{4}$ Conceito utilizado por Santos (2015). Ver "Apropriações da tradição marxista no Serviço Social".
} 
com o marxismo expressam uma ruptura com o conservadorismo que é mais política que teórica.

É interessante notar que esse processo não rompeu radicalmente com a herança conservadora, de cunho positivista e irracionalista, predominante, historicamente, no Serviço Social, o que vai se constituir num dos fatores explicativos da aproximação tardia da profissão ao debate do marxismo e à sua incorporação, por via de um marxismo positivista (SANTOS, 2015, p. 2).

Não por acaso, em 1985, o Programa de Pós-Graduação em Serviço Social da Pontifícia Universidade Católica de São Paulo (PUC-SP), traz ao Brasil para uma conferência sobre as ideologias e o processo de conhecimento científico o sociólogo marxista Michael Löwy. As gravações e transcrições dessa conferência tornaram-se depois uma das obras mais didáticas do autor sobre o tema ${ }^{5}$. E registram um momento importante do esforço do Serviço Social brasileiro para o amadurecimento da relação com o marxismo, objetivando afastar as distorções das polêmicas filosóficas que atravessavam e ainda atravessam as ciências humanas.

No Serviço Social, mesmo após algumas décadas de interlocução com o marxismo, permanecem vários traços de ecletismo e de utilização do marxismo exclusivamente como método para entendimento da realidade, negando o caráter de classe de sua teoria. Esta influência positivista no marxismo produz inflexões no debate sobre a disputa de projetos societários no seio da profissão.

A histórica influência positivista nas ciências humanas e sociais possui contornos contemporâneos. O critério da neutralidade e imparcialidade para auferir à pesquisa o caráter de ciência é dominante no universo acadêmico. Este é um dos motivos pelos quais o marxismo tem sido colocado cada dia mais no campo da marginalidade intelectual. $\mathrm{A}$ compreensão de que o capitalismo "venceu" os rumos da história e que, portanto, as elaborações marxistas perderam sua validade e utilidade social, soma-se ao desprezo do marxismo enquanto método, dada a clareza com que Marx situava os interesses e propósitos de suas elaborações.

Um fato recente é expressão do que afirmamos. No primeiro semestre de 2014, um projeto de pesquisa intitulado "Crise do capital e fundo público: implicações para o

\footnotetext{
${ }^{5}$ Referimo-nos ao livro chamado Ideologias e Ciência Social: elementos para uma análise marxista.
} 
trabalho, os direitos e as políticas sociais", elaborado por pesquisadores marxistas da área do Serviço Social brasileiro, teve seu financiamento negado pelo Programa Nacional de Cooperação Acadêmica (PROCAD), da Coordenação de Aperfeiçoamento de Pessoal de Nível Superior (CAPES). Entre os motivos apresentados no parecer de recusa, estava a utilização do marxismo enquanto metodologia de pesquisa, "cuja contribuição à ciência brasileira parece duvidosa", segundo o parecerista. O documento afirmava ainda que "[...] a utilização deste método não garante os requisitos necessários para que se alcance os objetivos do método científico" (KAPA, 2014).

O consenso em torno da necessária neutralidade nas ciências humanas, demonstrado pelo exemplo dado, possui um efeito muito mais amplo do que no campo da pesquisa. Espera-se não apenas do pesquisador, mas das profissões em geral e, neste caso, do Serviço Social a imparcialidade em torno de temas diversos, sobretudo os mais polêmicos. Não é raro ouvirmos de estudantes e de profissionais uma postura de isenção em relação a temas como o aborto e a diversidade sexual, para citar apenas alguns exemplos. Especialmente quando se trata de um conflito entre as crenças pessoais do profissional e a garantia dos direitos humanos, a saída encontrada diante de conflitos ideológicos seria uma postura profissional que se "isenta" de julgamentos e seja neutra. Não é incomum também ouvirmos questionamentos sobre a natureza da importância de o Serviço Social debater e inserir em sua agenda de lutas os temas citados anteriormente.

Entretanto, como já mencionamos, isentar-se de debater determinada temática não remete a uma postura de neutralidade. Se estivermos diante de uma situação de injustiça, em que determinado sujeito ou grupo encontra-se em situação de opressão e/ou exploração social e/ou política, e optarmos por nos isentar de posições em relação a essa situação, inevitavelmente estamos concordando que a situação de injustiça se prolongue, decidindo-nos por não fortalecer a luta pela libertação do oprimido. Ou seja, se diante da existência e crescimento da violência doméstica contra as mulheres, optamos por não nos posicionar, considerando, por exemplo, que este é um problema de foro íntimo, estamos compactuando com a ideologia machista que faz dezenas de vítimas diariamente e concordando, também, que a situação de violação de direitos se perpetue. Estamos escolhendo o outro lado. Este é apenas um exemplo, poderíamos dar milhares de outros. 


\title{
Os projetos profissionais no serviço social brasileiro
}

O Serviço Social brasileiro constitui em seus objetivos profissionais um projeto profissional. Este projeto se expressa desde as nossas diretrizes para formação à regulamentação do exercício profissional, passando pelo Código de Ética Profissional. Os projetos profissionais estão no marco dos projetos coletivos existentes na sociedade e expressam a forma como determinada profissão analisa a sociedade e o seu papel. Manifesta, também, a maneira como a profissão pretende ser vista pela sociedade, pois resulta na relação que o profissional terá com as outras profissões e com os usuários dos serviços prestados.

Segundo Paulo Netto (2006, p. 4):

\begin{abstract}
Os projetos profissionais apresentam a auto-imagem de uma profissão, elegem os valores que a legitimam socialmente, delimitam e priorizam seus objetivos $e$ funções, formulam os requisitos (teóricos, práticos e institucionais) para o seu exercício, prescrevem normas para o comportamento dos profissionais $e$ estabelecem as bases das suas relações com os usuários de seus serviços, com as outras profissões e com as organizações e instituições sociais privadas e públicas (inclusive o Estado, a que cabe o reconhecimento jurídico dos estatutos profissionais) (destaque nosso).
\end{abstract}

Como para existir uma profissão precisa ser legitimada socialmente, e, ao existir, existe em sociedade, as profissões e, portanto, os projetos profissionais apresentam “inelimináveis dimensões políticas, seja no sentido amplo (referido às suas relações com os projetos societários), seja em sentido estrito (referido às perspectivas particulares da profissão)" (PAULO NETTO, 2006, p. 5, grifo nosso).

Sendo assim, as profissões apresentam, para além dos exclusivos interesses profissionais, um interesse coletivo que ultrapassa o limite da profissão, abraçando toda a estrutura da sociedade.

Nos marcos de uma sociedade de classes, em que as classes fundamentais carregam interesses diametralmente antagônicos, os projetos societários são, necessária e simultaneamente, projetos de classe (PAULO NETTO, 2006, p. 2). Isto é, apresentam um projeto de sociedade que, em primeira ou em última instância, atenderá aos interesses fundamentais de uma ou outra classe social.

Isto acontece embora, nem sempre ou quase nunca, essa dimensão política dos projetos profissionais apareça de forma aberta, sobretudo quando se trata da defesa de 
projetos conservadores. Isto porque não é útil para os projetos conservadores - que, digase de passagem, são aqueles que pretendem conservar a sociedade como está, em nosso caso, manter a burguesia enquanto classe dominante - estabelecer de forma clara a disputa de projetos societários, posto que este projeto é hegemônico na sociedade e sua base de sustentação é, também, a alienação dos oprimidos e explorados, que não se identificam como tal.

É por este motivo que, como ilustra Paulo Netto (2006, p. 5):

\begin{abstract}
Um dos traços mais característicos do conservadorismo consiste na negação das dimensões políticas e ideológicas. Não é por acaso que o conhecido pensador lusitano Antônio Sérgio, numa passagem notável, tenha observado que "aquele que diz não gostar de política, adora praticar política conservadora".
\end{abstract}

Mas, mesmo que não se expresse claramente, a disputa de projetos profissionais - e societários - acontece. Nesse caso, no âmbito das profissões e, mais especificamente, em nossa profissão.

A história do Serviço Social brasileiro demonstra as formas variadas que o exercício profissional assume a partir do conteúdo político ao qual ele se vincula estrategicamente. Em uma perspectiva conservadora e conectada à reprodução da sociabilidade burguesa, por exemplo, "questões de economia política transformam-se em problemas assistenciais, e direitos da utilização de conquistas sociais do proletariado viram concessão de benefícios" (IAMAMOTO, 2011, p. 34). Do mesmo modo, o processo de vinculação da profissão a determinada teoria e direção social guarda relação direta com a realidade social, e é fruto de força ativa, organização política e disputa consciente, constituindo o corpo profissional como um espaço de permanentes tensões.

A direção teórico-política hegemônica do Serviço Social brasileiro passou por inúmeras mudanças ao longo da história da profissão. Nota-se, entretanto, durante as primeiras décadas de existência da profissão (referimo-nos às décadas de 1930 a meados da década de 1960), um marcante traço comum: o compromisso sociopolítico com o conservadorismo (IAMAMOTO, 2011).

Este traço comum foi a base da construção de um fazer profissional historicamente comprometido com o projeto de sociedade das classes dominantes, com uma função intelectual colaboracionista com a concepção de mundo burguesa (PEREIRA, 2007) na 
medida em que negava a existência das classes sociais e as expressões da questão social como consequências inerentes ao antagonismo entre capital e trabalho.

É pertinente demarcar que a trajetória intelectual percorrida é mediada pela conjuntura das origens da profissão. O Serviço Social brasileiro surge com um propósito conservador, em um momento sócio-histórico complexo, afetado pela luta de classes e pelo objetivo da burguesia, Estado e Igreja de doutrinação das massas operárias, que lutavam por direitos no processo de industrialização vivido pelo país neste momento. $A$ origem da profissão explica-se, entre outros fatores, pela necessidade de intervenção ideológica das classes dominantes sobre a classe trabalhadora. O Serviço Social surge, portanto, com os preceitos burgueses, em que:

Os efeitos da exploração capitalista do trabalho são reconhecidos e transformados em "problemas sociais", justificadores da ação profissional; mas não se colocam em questão as razões históricas dessa exploração. Este esquema de percepção permite conciliar a concepção humanista-cristã de vida e a exploração burguesa do trabalho (IAMAMOTO, 2011, p. 29).

Dessa forma, instala-se na profissão uma concepção de exercício profissional que almeja tratar os problemas sociais buscando soluções individuais, como se a pobreza, o desemprego e outras mazelas sociais fossem resultado de algum desajustamento individual ou familiar, e não um problema de fato social.

Em consonância com uma visão completamente desconectada das causas das expressões da questão social, que busca resolver desajustamentos ocasionais, o fazer profissional do assistente social no período que antecede a renovação configurava-se hegemonicamente em um fazer fundamentalmente técnico-operativo que almejava um ajustamento social dos indivíduos, negando a necessidade da formação teórica para a intervenção profissional.

Nesta perspectiva, há também uma forte tendência pragmática, de negação das ciências sociais e da ação reflexiva sobre a sociedade. Reivindica-se a observação e a experiência empírica, ao considerar que a teoria não serve para reformar a vida e a sociedade (IAMAMOTO, 2011). Imprime um sentido utilitarista à teoria, ao pensar a realidade na sua imediaticidade $e$ ao buscar agir sobre ela com esta racionalidade (GUERRA, 2014).

Estes são os elementos de sustentação do discurso e da prática dos assistentes sociais durante as primeiras décadas da profissão, que vão se expressar na busca pela 
resolução da "crise da profissão" pela via do maior aperfeiçoamento técnico-instrumental (IAMAMOTO, 2011), levando às diferentes fases de intervenção profissional. Seja a fase embrionária mais ligada à caridade, a fase posterior de busca pelo ajustamento individual e coletivo, ou ainda a tendência à psicologização das relações sociais. Em todas essas fases, até o período do Regime Militar, observa-se a prevalência da discussão da metodologia profissional, buscando encontrar e aperfeiçoar os traços peculiares da profissão: objeto, objetivos, métodos e procedimentos de intervenção (IAMAMOTO, 2011). Estas fases expressam a busca por encontrar no aperfeiçoamento profissional a resolução para os problemas com os quais o Serviço Social trabalhava.

Somente na década de 1970, após a Reforma Universitária de 1968, com a inserção do Serviço Social em ambientes universitários e, notadamente, com a conjuntura de lutas sociais e questionamentos ao regime militar, que sinalizou o início de um período de profundos questionamentos quanto à direção social do Serviço Social (PEREIRA, 2007, p. 223).

Assim, de um profissional incumbido de transformar demandas por direitos sociais em "desajustes" e/ou "patologias sociais" o assistente social passou a pautar-se pelo reconhecimento de uma sociedade dividida em classes sociais e pela condição estratégica da luta por direitos sociais. Deste modo, o processo de renovação profissional possibilitado contraditoriamente, entre outros fatores, pelo Estado brasileiro por meio da laicização e expansão da profissão com a inserção do processo formativo em ambientes universitários - desencadeou um movimento de construção de um pluralismo teórico, ideológico e político profissional. Tal processo proporcionou, ainda, a construção de um projeto profissional cuja pauta, nos anos 1980, foi a de ruptura com o histórico conservadorismo do Serviço Social (PEREIRA, 2007, p. 223).

Este movimento de construção de um novo direcionamento teórico, ideológico e político na profissão apresenta sua ambiência sócio-histórica, ideopolítica e cultural no avanço das lutas sociais dos anos 1980 (ABRAMIDES; CABRAL, 2009). Os avanços intelectuais pelos quais passou a profissão delegam o protagonismo, mas não exclusividade, dessas transformações à relação com a teoria marxista, pois são também parte de um movimento de avanço da consciência do conjunto da classe trabalhadora brasileira. 
Acontecem inúmeras mudanças na conjuntura que darão novos contornos à trajetória política da profissão. São anos que provocarão mudanças nas bases teóricas, éticas, políticas e organizativas na categoria: uma verdadeira "virada" no projeto profissional.

O período histórico brasileiro de meados do final de 1970 a meados dos anos 1980 marcado pela crise do petróleo e da ditadura militar brasileira - foi de intensas lutas no Brasil, surgindo ou ressurgindo, justamente nesse período histórico, as grandes organizações sindicais, estudantis e partidárias com clara identidade classista.

Embora a ditadura militar brasileira tenha se utilizado do discurso do crescimento econômico acelerado, conhecido como "milagre econômico", para convencer a sociedade do progresso que vivia o país, as contradições do período logo se mostraram. Apesar dos altos índices de crescimento da economia, a qualidade de vida das camadas mais pauperizadas da população não melhorou nesse período. Pelo contrário, parte do crescimento econômico sustentou-se em um profundo arrocho salarial já que "o custo de vida, de 1962 a 1969, teve um índice de aumento de 100 para 1.492, e o salário real passou de 100 para 122" (SINGER, 1985, apud FALEIROS, 2009, p. 44), e "segundo a Fundação Getúlio Vargas a taxa anual de inflação foi 19,3\% em 1970 e de 77,2\% em 1979" (FALEIROS, 2009, p. 44).

A insatisfação com o regime tinha, então, base material no declínio do poder de compra dos trabalhadores no período. Os anos finais da ditadura foram os anos que proporcionaram uma das maiores acumulações de renda no país. Em 1960, os 10,0\% mais ricos da população tinham uma participação no PIB que correspondia a 39,66\%, percentual que se elevou de maneira extraordinária para $46,8 \%$ em 1984 . Ao mesmo tempo que os $1,0 \%$ mais ricos do país tinham uma concentração de renda superior aos $50,0 \%$ mais pobres da população (WELMOWICKI, 2004, p. 48).

A insatisfação já era tão forte que, na tentativa de conter as lutas sociais, o Governo Geisel propõe "abertura controlada" do regime, com aumento progressivo do poder de eleição direta pelo povo dos governantes. Esse movimento por parte dos governos ditatoriais, entretanto, não foi capaz de conter o assenso do movimento operário, pois "o acúmulo das tensões sociais durante a ditadura gerou um fenômeno explosivo, mas de 
classe, de identificação política ampla dos trabalhadores e que o sucesso das primeiras greves tornou estendido em escala nacional" (WELMOWICKI, 2004, p. 51).

Dessa forma, as 270 greves, com adesão de 140.000 trabalhadores em 1978, são superadas por cerca de 1.400.000 grevistas em 1979 (MATTOS, 2014), em que se destacam as lutas dos metalúrgicos de São Paulo, das quais surgiram as principais lideranças sindicais e políticas da classe trabalhadora e que sustentaram, posteriormente, o impulso para a criação do Partido dos Trabalhadores (PT). Nesse período, destaca-se como liderança dos metalúrgicos do $A B C$ paulista, Luís Inácio da Silva, o Lula.

Havia também um forte movimento pelas Diretas já (luta por direito às eleições diretas pela população dos parlamentares do legislativo e executivo), que aglutinava estudantes, trabalhadores - operários e servidores públicos - artistas e demais movimentos sociais.

Todo esse processo de desgaste dos direitos trabalhistas e das condições de vida da população, aliado à repressão política a toda oposição ao governo militar brasileiro, abriu um processo de esgotamento que culminou com uma intensa organização das lutas na sociedade brasileira. Entra em cena a classe trabalhadora brasileira, num momento em que

a orientação dada às políticas sociais pelos governos da ditadura [gerava] grandes [...] dificuldades de inserção no mercado de trabalho, além de uma queda geral nos salários praticados pela indústria e pelo comércio, sobretudo nos setores de média e baixa qualificação (MARTINELLI, 2009, p. 97).

É também nesse período, e sob a influência desta conjuntura, que se fortalece no Serviço Social uma vertente crítica ao projeto profissional conservador. Embora existissem diversos setores conservadores na profissão, é nessa conjuntura que amadurece no Serviço Social "um processo organizativo de luta social, combativa, ao lado dos movimentos sociais de base que se processavam na sociedade brasileira" (MARTINELLI, 2009, p. 98).

Data-se de meados de 1977 o período de reorganização sindical e política dos assistentes sociais. Este período de reorganização esteve profundamente ligado à conjuntura de lutas da classe trabalhadora em geral, na medida em que se vinculou diretamente ao novo sindicalismo, que se contrapunha ao sindicalismo predominante no período de conciliação de classes. 
O processo de ruptura com o conservadorismo na profissão se gesta e se constrói em meio à reorganização política e sindical de toda a classe trabalhadora e tem estreito laço com essa conjuntura e com os demais sujeitos políticos da classe trabalhadora no período.

Entretanto, é importante demarcar que este não foi um processo harmônico e homogêneo, mas um processo aberto de disputa pela hegemonia do projeto profissional da categoria, que prescindiu de importantes sujeitos individuais e coletivos.

Na década seguinte, 1990, mantém-se o mesmo ritmo da intenção de ruptura com os ideais conservadores consagrando importantes reformulações nos marcos regulatórios da profissão, como o Código de Ética profissional (1993), a Lei de Regulamentação (1993) e o estabelecimento das Diretrizes Curriculares (1996) para o curso de Serviço Social nas universidades. Todas estas mudanças somam-se a muitas vitórias conquistadas pela classe trabalhadora num plano mais geral, tais como a Constituição de 1988 e seus desdobramentos nas políticas públicas, que também foram essenciais para a consolidação não só da profissão, mas para a efetivação dos direitos sociais.

O projeto ético-político vai ganhando corpo e forma na categoria. É por isso que se considera que este "projeto avançou nos anos 1980, consolidou-se nos 1990 e está em construção [...]" (BRAZ; TEIXEIRA, 2009, p. 13, grifo nosso). Os anos 1980 significam, portanto, os anos de crescimento da participação política da categoria nas lutas gerais e nos espaços da profissão, de crescimento da produção intelectual, por meio da criação dos cursos de pós-graduação e maior incentivo à realização de pesquisas, - com o estreitamento da profissão com a teoria social crítica de Marx - e com os avanços na organização político-profissional, que tem sua materialização mais visível nos anos 1990.

Configuram-se, então, com o passar dos anos, o que se chama de elementos ou componentes que materializam o Projeto ético-político (BRAZ; TEIXEIRA, 2009, p. 8), que se convencionou separar - para fins didáticos - em três esferas centrais: a esfera da produção de conhecimento, quem tem ligação direta com a pesquisa e a pós-graduação embora, de forma nenhuma, se limite a ela; a esfera político-organizativa, que diz respeito às entidades e fóruns coletivos construídos historicamente, de discussão, consulta e deliberação da categoria e dos estudantes; a esfera jurídica-política "na qual se constitui o arcabouço legal e institucional da profissão, que envolve um conjunto de leis e resoluções, documentos e textos políticos consagrados no seio da profissão". 
Compreendemos, portanto, que essa síntese de elementos busca levar à existência concreta da profissão o sentido de seu projeto. Ou seja, busca materializar o projeto profissional dando sentido às ações dos membros desta categoria profissional. Cabe situar, entretanto, que quando enfatizamos que a normatização, leis, organização, posicionamentos e formação do Serviço Social buscam garantir um sentido profissional que alcance determinado projeto ético-político e societário na realidade, estamos dizendo que esse "resultado" não é absoluto e automático.

A formação e o exercício profissional enfrentam grandes desafios, adversos ao projeto ético-político, que se expressam no âmbito estritamente profissional - por meio da precarização da formação, em que se destaca o crescimento de cursos de graduação a distância; e por meio da precarização do exercício profissional, por meio da acentuada degradação das condições de trabalho - mas também no âmbito mais geral, que afetam toda a classe trabalhadora - nos marcos de uma conjuntura cada vez regressiva para os interesses imediatos e históricos daqueles que vivem do trabalho.

Esta categoria, embora tenha construído um projeto crítico hegemônico e elaborado mecanismos que marcham no sentido de tornar possíveis posturas coerentes com tal projeto, enfrenta, cotidianamente, um processo que é permeado por contradições, já que "a afirmação e consolidação de um projeto profissional em seu próprio interior não suprimem as divergências e contradições" (PAULO NETTO, 2006, p. 5). Ele ainda discorre que:

O corpo profissional é uma unidade não homogênea, uma unidade de diversos; nele estão presentes projetos individuais e societários diversos e, portanto, configura um espaço plural do qual podem surgir projetos profissionais diferentes. [...] Mais exatamente, todo corpo profissional é um campo de tensões e de lutas (PAULO NETTO, 2006, p. 5)

Disputamos cotidianamente com um projeto conservador, de conservação da sociedade, o projeto da burguesia, as mentes e corações dos indivíduos de forma desigual, por ser projeto da classe dominante possuir os principais meios de comunicação e difusão de ideologias.

\section{Considerações finais}

A síntese dessa discussão aponta no sentido de tirarmos algumas conclusões acerca das experiências históricas vividas pela profissão, bem como apontar elementos para análise e reflexão diante dos desafios existentes no tempo presente. 
Começamos afirmando que não existe neutralidade nas ciências sociais, nas profissões, na sociedade, e fizemos um breve resgate da trajetória intelectual e política da profissão.

Queremos tirar disso algumas conclusões: a) a história do Serviço Social é diretamente influenciada pela conjuntura, pela realidade social, pela luta de classes, sendo todos os avanços e retrocessos vinculados à dinâmica mais geral da sociedade; b) nossa história também reafirma a não existência da neutralidade, mas não apenas isso: demonstra que a hegemonia de determinado projeto profissional não garante a homogeneidade - o corpo profissional é diverso e as disputas existem de forma permanente; c) demonstra, ainda, que a disputa dos projetos profissionais e societários acontece prioritariamente por meio da organização coletiva.

Neste sentido, o que estamos aqui propondo como reflexão, a título de conclusão, é que não há neutralidade: nem na formação, nem no exercício profissional. E, não havendo neutralidade, existem posições ético-políticas variadas que podemos adotar, cabendo a nós - individual ou coletivamente - essa escolha.

\section{Referências}

ABRAMIDES, M. B. C.; CABRAL, M. S. A organização política do Serviço Social e o papel da CENEAS/ANAS na virada do Serviço Social brasileiro. In: CONSELHO FEDERAL DE SERVIÇO SOCIAL - CFESS (Org.). 30 anos do Congresso da Virada (1979-2009). Brasília: CFESS, 2009. p. 55-78.

BRAZ, M.; TEIXEIRA, J. B. O projeto ético-político do serviço social. In: CONSELHO FEDERAL DE SERVIÇO SOCIAL - CFESS. Serviço social: direitos sociais e competências profissionais. Brasília: CFESS/ABEPSS, 2009. Disponível em:

<http://www.prof.joaodantas.nom.br/materialdidatico/material/4_-_O_projeto_eticopolitico_do_Servico_Social.pdf>. Acesso em: 2 jun. 2015.

FALEIROS, V. P. O Congresso Brasileiro de Assistentes Sociais na conjuntura dos anos 70. In: CONSELHO FEDERAL DE SERVIÇO SOCIAL - CFESS (Org.). 30 anos do Congresso da Virada (1979-2009). Brasília: CFESS, 2009. p. 43-54.

IAMAMOTO, M. V. Renovação e conservadorismo no serviço social. 11. ed. São Paulo: Cortez, 2011.

GUERRA, Y. Transformações societárias e serviço social: repercussões na cultura profissional. In: MOTA, A. E.; AMARAL, A. Serviço social brasileiro nos anos 2000: cenários, pelejas e desafios. Recife: Ed. UFPE, 2014. 
KAPA, R. Governo nega projeto por ser marxista e revolta pesquisadores da Unb-UerjUfrn. O Globo, São Paulo, 6 jun. 2014. Disponível em: <http://oglobo.globo.com/sociedade/educacao/governo-nega-projeto-por-ser-marxistarevolta-pesquisadores-da-unb-uerj-ufrn-12745626\#ixzz3LdJ4bQOK>. Acesso em: 2 jun. 2015.

LÖWY, M. Método dialético e teoria política. 3. ed. São Paulo: Paz e Terra Filosofia, 1985. . Ideologias e ciência social: elementos para uma análise marxista. 18. ed. São Paulo: Cortez, 2008.

As aventuras de Karl Marx contra o Barão de Münchhausen: marxismo e positivismo na sociologia do conhecimento. 10. ed. São Paulo: Cortez, 2013.

MARTINELLI, M. L. A perspectiva do II Congresso Brasileiro de Assistentes Sociais. In: CONSELHO FEDERAL DE SERVIÇO SOCIAL - CFESS (Org.). 30 anos do Congresso da Virada (1979-2009). Brasília: CFESS, 2009. p. 97-104

MATTOS, M. B. Movimento sindical brasileiro: o desafio da reorganização. In: ABRAMIDES, M. B; DURIGUETTO, M. L. (Org.). Movimentos sociais e serviço social: uma relação necessária. São Paulo: Cortez, 2014.

PAULO NETTO, J. A construção do projeto ético-político do serviço social. In: MOTA, A. E. et al. (Org.). Serviço social e saúde: formação e trabalho profissional. São Paulo: Cortez, 2006. p. 141-160.

PEREIRA, L. D. Política educacional brasileira e Serviço Social: do confessionalismo ao empresariamento da formação profissional. 2007. 378 f. Tese (Doutorado em Serviço Social) - Escola de Serviço Social, Universidade Federal do Rio de Janeiro, Rio de Janeiro, 2007.

SANTOS, J. S. Apropriações da tradição marxista no Serviço Social. Disponível em: <http://pt.slideshare.net/mauxa/cadernos421-14907072>. Acesso em: 15 jan. 2015.

WELMOWICKI, J. Cidadania ou classe? O movimento operário da década de 80. São Paulo: Sundermann, 2004.

Recebido em: 02/06/2015

Aprovado em: 20/06/2015 